\title{
Laparoscopic Roux-en-Y Gastric Bypass for the Treatment of Type II Diabetes Mellitus in Chinese Patients with Body Mass Index of 25-35
}

\author{
Chih-Kun Huang • Asim Shabbir • Chi-Hsien Lo • \\ Chi-Ming Tai $\cdot$ Yaw-Sen Chen $\cdot$ Jer-Yiing Houng
}

Published online: 9 April 2011

(C) The Author(s) 2011. This article is published with open access at Springerlink.com

\begin{abstract}
Background Laparoscopic Roux-en-Y gastric bypass (LRYGB) can dramatically ameliorate type 2 diabetes mellitus (T2DM) in morbidly obese patients. However, there is little evidence supporting the effectiveness of LRYGB in low body mass index (BMI) patients. The study was designed to evaluate the safety and results of LRYGB for achieving $\mathrm{T} 2 \mathrm{DM}$ remission in patients with $\mathrm{BMI}$ in the range of $25-35 \mathrm{~kg} / \mathrm{m}^{2}$.

Methods Twenty-two patients (two men and 20 women) with T2DM underwent LRYGB. Data on patient demographics, BMI, co-morbidities, and details of diabetes mellitus, including disease duration, family history, medication use, and remission, were prospectively collected and analyzed.

Results The mean age was 47 years (range, 28-63 years), mean BMI was 30.81 (range, $25.00-34.80 \mathrm{~kg} / \mathrm{m}^{2}$ ), and mean duration of T2DM onset was 6.57 years (range,
\end{abstract}

C.-K. Huang $\cdot$ A. Shabbir $\cdot$ C.-H. Lo

Bariatric \& Metabolic International Surgery Center,

E-Da Hospital,

Kaohsiung, Taiwan

C.-K. Huang • Y.-S. Chen

Department of General Surgery, E-Da Hospital,

Kaohsiung, Taiwan

C.-K. Huang · J.-Y. Houng $(\bowtie)$

Department of Chemical Engineering, Institute of Biotechnology and Chemical Engineering, I-Shou University,

1, E-Da Road, Yan-Chau Region,

Kaohsiung 824, Taiwan

e-mail: jyhoung@isu.edu.tw

C.-M. Tai

Department of Internal Medicine, E-Da Hospital,

Kaohsiung, Taiwan
1-20 years). Sixteen (72.27\%) patients had a family history of T2DM. There was no mortality, but two (9\%) patients experienced complications: an early gastrojejunostomy hemorrhage and frequent loose stools that required revision surgery. At 12 months, 14 (63.6\%) patients showed T2DM remission, six (27.3\%) showed glycemic control, and two (9.1\%) showed improvement. The group achieving remission had a higher BMI $(p=0.001)$, younger age $(p=0.002)$, and shorter duration of diabetes $(p=0.001)$. These three factors may be predictors of diabetes resolution at 12 months.

Conclusion Early intervention in low-BMI patients yields better remission rates because age, BMI, and duration of T2DM predict glycemic outcomes.

Keywords Laparoscopic Roux-en-Y gastric bypass . Type II diabetes mellitus · Low BMI

\section{Introduction}

Diabetes is a chronic progressive disease and is undoubtedly the most common endocrine disorder worldwide. According to projections by $\mathrm{WHO}$, its prevalence will reach a staggering 334 million people worldwide by the year 2025 [1]. Currently, medical treatment, including diet, exercise, and anti-diabetic medications, is the mainstay for managing type 2 diabetes mellitus (T2DM). However, there is increasing evidence that surgery can help achieve complete remission, especially in morbidly obese patients with diabetes [2]. The positive effects of bariatric surgery on the remission of T2DM are well established [3-5]. Several conventional and experimental surgical operations can dramatically ameliorate T2DM. While the benefits of gastric bypass surgery for treating obese patients with 
diabetes have been discussed in the literature, there is little evidence to support the effectiveness of this surgery in T2DM patients with low body mass index (BMI) [6].

Our study aims to prospectively evaluate the results of laparoscopic Roux-en-Y gastric bypass (LRYGB) surgery in patients with a BMI of $25-35 \mathrm{~kg} / \mathrm{m}^{2}$ in order to achieve T2DM remission.

\section{Material and Methods}

The study was conducted with the approval of the ethics committee and institutional review board of the E-Da Hospital (EMRP-097-106). All patients gave written informed consent after being made aware of the current standards of treatment for T2DM and understanding the risks and benefits associated with the procedure. Inclusion criteria for this study were as follows: age from 18 to 65 years, BMI from 25 to $34.9 \mathrm{~kg} / \mathrm{m}^{2}$, and poorly controlled T2DM as reflected by glycosylated hemoglobin (HbA1C) level of $\geq 7 \%$. Diagnosis of T2DM was based on the criteria of the American Diabetes Association (ADA) and was considered valid if established by an endocrinologist or diabetes specialist [7]. Before the operation, patients were assessed by a specialized team, including a surgeon, an endocrinologist, an anesthetist, a psychiatrist, and a dietician. All patients underwent routine a preoperative work-up and counseling in addition to a detailed diabetic work-up. Patients younger than 18 years or older than 65 years; those planning a pregnancy within 2 years after entry into this study; and those with established diagnoses of type 1 diabetes, latent autoimmune diabetes in adults, malignancy, debilitating disease, unresolved psychiatric illness, or substance abuse were excluded from the study.

We employed the previously reported LRYGB technique [8]. Data were collected prospectively and entered into a database. We collected data on patient demographics; BMI; co-morbidities; and details of the diabetes mellitus status, including the duration of disease, family history, and medication use. Operative details recorded were operation time, duration of hospitalization, and complications noted until the last follow-up session. In addition to the data from routine preoperative investigations, data on fasting plasma glucose (FPG), fasting C-peptide, and $\mathrm{HbAlc}$ levels were collected. Follow-up visits were scheduled at 1 week and at $1,3,6,9$, and 12 months after surgery. Postoperative data collected included levels of FPG, fasting C-peptide and $\mathrm{HbAlc}$, medication usage, and BMI.

The goals for glycemic and blood pressure controls were based on the criteria established by the ADA [9]. If patients were not taking anti-diabetic medications and had a normal FPG of $<100 \mathrm{mg} / \mathrm{dL}$ and a normal $\mathrm{HbAlc}$ of $<6 \%$, their condition was considered resolved. Those with an $\mathrm{HbA} 1 \mathrm{c}$ of $\leq 7 \%$ despite no use of anti-diabetic medications were said to have achieved glycemic control. If the FPG decreased by $>25 \mathrm{mg} / \mathrm{dL}$ or the $\mathrm{HbA} 1 \mathrm{c}$ reduced $>1 \%$, the patients' condition was considered to have improved. Surgery was considered to have failed if glycemic indices showed no significant improvement or worsened or if a patient required additional anti-diabetic medication.

\section{Statistical Analysis}

The means and standard deviations (SDs) were computed for continuous variables and evaluated using independent $t$ tests. Categorical variables are presented as numbers and percentages. Follow-up comparisons were analyzed using the paired $t$ test. When $20 \%$ of the cells had expected values of $<5$, Fisher's exact test was used instead. All statistics were two-tailed and were calculated with SPSS statistical software (version 15.0; SPSS Inc., Chicago, IL, USA). Values of $p<0.05$ were considered statistically significant.

\section{Results}

In this study, 22 patients (two men and 20 women) with T2DM underwent LRYGB between December 2008 and January 2010. The mean age was 47.36 (11.16) years (range, 28-63 years). The preoperative mean BMI was 30.81 (3.24) (range, $\left.25.00-34.80 \mathrm{~kg} / \mathrm{m}^{2}\right) ; 10(45.5 \%)$ of the patients had BMIs of $25-29.99 \mathrm{~kg} / \mathrm{m}^{2}$, and $12(54.5 \%)$ had BMIs of $30-34.99 \mathrm{~kg} / \mathrm{m}^{2}$. The mean duration from the onset of T2DM was 6.57 (6.34) years (range, 1-20 years). Sixteen (72.27\%) patients had a family history of T2DM. Oral hypoglycemic agents (OHGA) were used by 15 (68.1\%) patients before the operation. One (4.5\%) patient required insulin therapy. Three patients $(13.6 \%)$ were receiving both insulin and OHGA. Three (13.6\%) other patients had discontinued medication for no reason. Fifteen (68.1\%) patients had multiple co-morbidities. Fourteen (63.6\%) patients had hyperlipidemia; 13 (59\%), hypertension; 10, (45.4\%) steatohepatitis; and two, (9\%) gouty arthritis.

We were able to successfully complete LRYGB in all patients. The mean operative time was 72.8 (18.2) min (range, 45-134 $\mathrm{min}$ ). The mean duration of hospitalization was 2.41 (0.73) days (range, 2-4 days). There was no mortality, but two $(9 \%)$ patients developed complications: One patient had an early hemorrhage at the gastrojejunostomy site, and the other had frequent loose stools.

All of the 22 patients were followed up for 12 months. The changes in BMI at 1 year in comparison to the mean 
Fig. 1 Changes in mean BMI over time

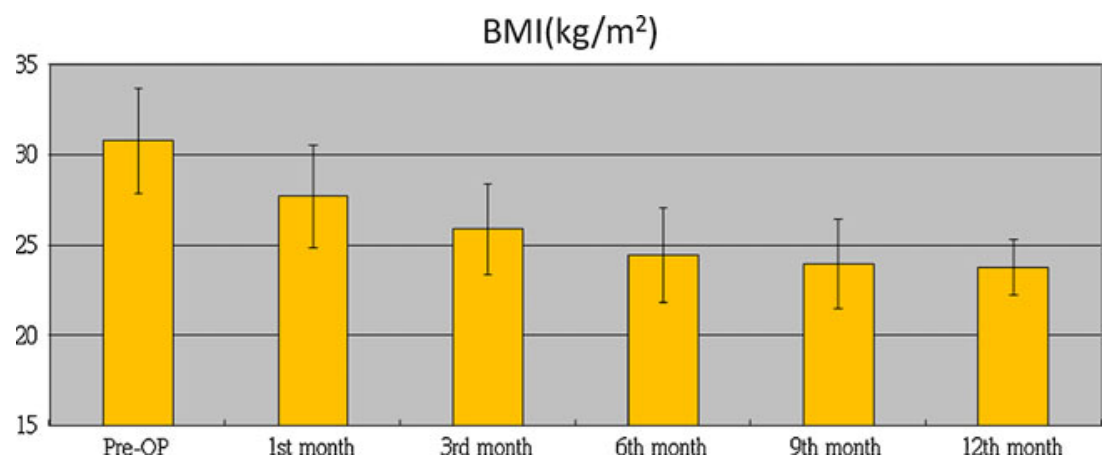

preoperative BMI were significant $(p<0.001)$, and the mean BMI dropped from 30.8 (2.9) preoperatively to 24.4 (2.6) at the sixth month and 23.7 (1.6) at the 12th month; nevertheless, the BMIs remained within the normal range (Fig. 1).

LRYGB resulted in a marked improvement in the biochemical markers of diabetes. Fasting C-peptide levels were assessed in 10 patients with a mean BMI of 29.4 (24.7-34.7), and they significantly dropped after surgery, from preoperative values of $3.74(2.44) \mathrm{ng} / \mathrm{ml}$ to 1.94 (1.29) $\mathrm{ng} / \mathrm{ml}$ at the first month $(p=0.002), 1.90(0.92) \mathrm{ng} / \mathrm{ml}$ at the third month $(p=0.009), 1.88(0.82) \mathrm{ng} / \mathrm{ml}$ at the sixth month $(p=0.013)$, and $1.88(1.07) \mathrm{ng} / \mathrm{ml}$ at 1 year $(p=0.005)$. Figures 2 and 3 demonstrate the improvement in FPG and HbA1c, respectively, during the course of 1 year. FPG and $\mathrm{HbA1c}$ significantly decreased from their preoperative values of $204.2(88.3) \mathrm{mg} / \mathrm{dL}$ and $9.2 \%$ to 113.5 (42.5) $\mathrm{mg} / \mathrm{dL}$ and $6.3 \%(p<0.001)$ at 6 months and to $103.5(27.6)$ $\mathrm{mg} / \mathrm{dL}$ and $5.9 \%(p<0.007)$ at 12 months, respectively. FPG was normalized in seven (31.4\%) patients at the first month, and $\mathrm{HbA} 1 \mathrm{c}$ was normalized in $14(63.6 \%)$ patients at the sixth month. At the 12th month, 14 (63.6\%) patients achieved remission of T2DM, six (27.3\%) showed glycemic control, and two (9.1\%) showed improvement. Twenty patients (90.3\%) did not need any medication. Only two patients still needed OHGA, and they had used a combination of OHGA and insulin therapy before the operation. All patients showed either an improvement or remission with regard to glycemic control. We found that the group that achieved remission after 12 months seemed to have higher BMI $(p=0.001)$, younger age $(p=0.002)$, and a shorter duration of diabetes $(p=0.001)$ (Table 1).

In addition, we did an analysis of the remission rate on the basis of the Asia-Pacific surgical criteria of morbid obesity, according to which the BMI should be $\geq 32$ [10]. There were 14 patients whose BMI was $<32$, of whom only six $(42.8 \%)$ patients achieved remission after surgery. The other eight patients achieved glycemic control or showed improvement in diabetes mellitus. To compare with the $100 \%$ remission rate of eight patients with a BMI of $>32$, the result is significantly different $(p=0.018)$.

\section{Discussion}

Diabetes encompasses a group of chronic progressive metabolic diseases that are characterized by hyperglycemia resulting from defects in insulin secretion or action or both
Fig. 2 Changes in mean fasting plasma glucose (FPG) over time

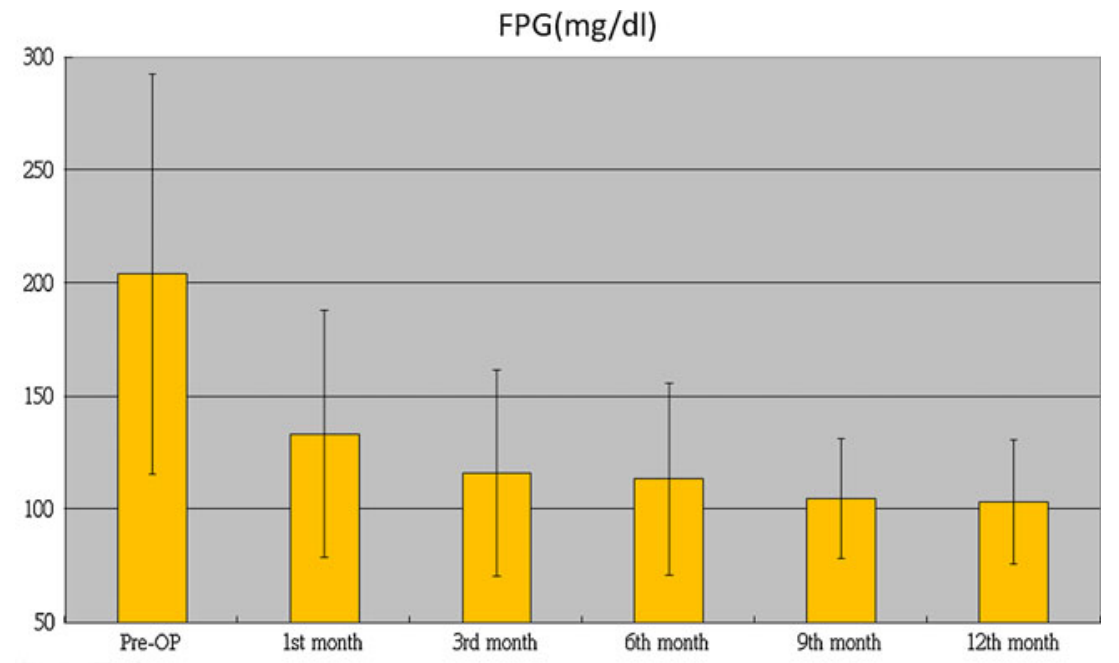


Fig. 3 Changes in mean $\mathrm{HbAlc}$ over time
$\mathrm{HbA} 1 \mathrm{c} \%$

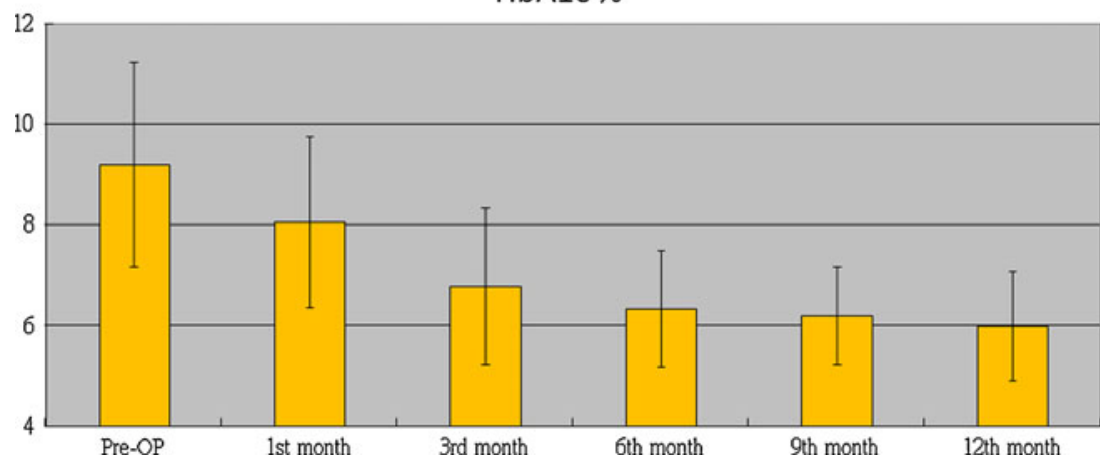

[11]. Diabetes is grouped into four clinical classes, and T2DM is the most common form of diabetes worldwide.

In the medical management of T2DM, the treatment goal is to achieve glycemic control in order to reduce complications; this is different from the potential novel end point of euglycemia that metabolic surgery offers [12]. A metaanalysis that summarizes diabetic outcomes of 3,188 patients reports a resolution rate of $80.3 \%$ with LRYGB, 95.1\% after biliopancreatic diversion (BPD), and 56.7\% after laparoscopic adjustable gastric banding (LAGB) in morbidly obese individuals [5]. The effects of bariatric procedures on the metabolic outcomes in individuals who are operated outside the NIH guidelines (i.e., patients with a BMI of $<35 \mathrm{~kg} / \mathrm{m}^{2}$ ) have been both interesting and controversial [13]. Since the first report on the amelioration of diabetes after subtotal gastrectomy in non-obese individuals by Friedmann et al., interest in metabolic surgery and the body of evidence supporting its use continues to grow [14-19]. Metabolic surgery - in particular, surgery for the amelioration of T2DM-marks the dawn of a new era in surgery. Although the exact mechanisms that govern the resolution of diabetes after surgery are poorly understood, innovative procedures based on the current understanding of mechanisms, such as duodenojejunal bypass and ileal interposition, are the subject of investigational studies on the amelioration of diabetes [20-23]. LRYGB is known to achieve sustainable resolution of diabetes in morbidly obese individuals [24]. This technique has been employed for ameliorating diabetes in patients with low BMI, and the short-term results from three such studies have been encouraging [17, 25, 26].

Bariatric procedures are typically designed to induce weight loss. Many critics have discussed the extrapolation of the metabolic results of such procedures for justifying
Table 1 Preoperative predictors of T2DM remission

Continuous variables are presented as mean (standard deviation) and categorical variables are presented as number (\%)

$B M I$ Body mass index;

$H b A 1 C$ xglycosylated

hemoglobin;

$H D L$ high density lipoprotein;

$L D L$ low density lipoprotein;

$O H G A$ oral hypoglycemic agent

${ }^{*} p<0.05$, statistically significant difference between the two groups

${ }^{\mathrm{a}} p$ values were calculated by independent $t$ test

${ }^{\mathrm{b}} p$ values were calculated by Fisher's exact test

\begin{tabular}{|c|c|c|c|}
\hline Parameters & Remission, $N=14$ & Glycemic control/improvement, $N=8$ & $p$ value \\
\hline Age $(\text { years })^{\mathrm{a}}$ & $41.69(10.77)$ & $55.56(5.028)$ & $0.002 *$ \\
\hline \multicolumn{3}{|l|}{ Gender $(\%)^{\mathrm{b}}$} & \multirow[t]{3}{*}{0.494} \\
\hline Women & $11(84.6)$ & $9(100.0)$ & \\
\hline Men & $2(15.4)$ & $0(0.0)$ & \\
\hline BMI $\left(\mathrm{kg} / \mathrm{m}^{2}\right)^{\mathrm{a}}$ & $32.37(2.57)$ & $28.06(2.30)$ & $0.001 * * *$ \\
\hline Glucose $(\mathrm{mg} / \mathrm{dL})^{\mathrm{a}}$ & $192.92(81.47)$ & $231.22(94.56)$ & 0.338 \\
\hline $\operatorname{HbA1C}(\%)^{\mathrm{a}}$ & $9.02(2.10)$ & $9.52(1.95)$ & 0.568 \\
\hline Total cholesterol (ng/dL) ${ }^{\mathrm{a}}$ & $195.07(104.47)$ & $191.56(41.93)$ & 0.925 \\
\hline Triglyceride (ng/dL) ${ }^{\mathrm{a}}$ & $170.08(46.23)$ & $196.56(43.41)$ & 0.188 \\
\hline $\operatorname{HDLC}(\mathrm{ng} / \mathrm{dL})^{\mathrm{a}}$ & $44.58(6.72)$ & $46.29(9.03)$ & 0.674 \\
\hline $\operatorname{LDLC}(\mathrm{ng} / \mathrm{dL})^{\mathrm{a}}$ & $128.83(42.02)$ & $113.57(25.00)$ & 0.397 \\
\hline Duration of DM (years) & $3.08(2.71)$ & $11.22(6.91)$ & $0.001 * * *$ \\
\hline \multicolumn{3}{|l|}{ DM family history $(\%)^{\mathrm{c}}$} & \multirow[t]{3}{*}{0.376} \\
\hline No & $3(23.1)$ & $4(44.4)$ & \\
\hline Yes & $10(76.9)$ & $5(55.6)$ & \\
\hline \multicolumn{3}{|l|}{ OHGA $(\%)^{\mathrm{b}}$} & \multirow[t]{3}{*}{0.616} \\
\hline No & $3(23.1)$ & $1(11.1)$ & \\
\hline Yes & $10(76.9)$ & $8(88.9)$ & \\
\hline \multicolumn{3}{|l|}{ Insulin therapy $(\%)^{\mathrm{b}}$} & \multirow[t]{3}{*}{1.000} \\
\hline No & $11(84.6)$ & $7(77.8)$ & \\
\hline Yes & $2(15.4)$ & $2(22.2)$ & \\
\hline
\end{tabular}


their application in T2DM patients with BMIs below the cut-off as per NIH guidelines. In this study, all patients experienced weight loss because of which they were in either the normal or overweight category; none were underweight. Other studies concerning LRYGB performed on patients with low BMIs corroborate the finding of a less dramatic postoperative change in BMI $[17,26]$. A possible explanation postulated by Scopinaro et al. is that a homeostatic mechanism permits weight loss relative to the amount of calories for which the procedure facilitates its absorption. Furthermore, there is blunting of weight loss [19].

The mean operating time and duration of hospitalization in our study were $72.86 \mathrm{~min}$ and 2.41 days, respectivelyhalf the corresponding values (153.6 min and 4.5 days, respectively) for morbidly obese patients undergoing LRYGB [8]. We believe that the shorter operating time was the result of a lower BMI because our surgical technique remained unchanged. Although expansion of LRYGB criteria to include low-BMI patients with T2DM is attractive, the issue of safety needs to be addressed. There was no mortality in the present study, and the overall morbidity of $9 \%$ was similar to that of $10.3 \%$ for malabsorptive/restrictive procedures in low-BMI patients, as mentioned in a report by Fried et al. [27]. Early hemorrhage from the gastrojejunal anastomosis occurred in one patient and was conservatively managed with blood transfusion. Another female patient experienced frequent loose stools after the procedure. In a study by Lee et al., $6.2 \%$ and $2.2 \%$ of the patients had minor and major complications, respectively [26]. The overall complication rate in our study appears reasonable. However, T2DM is well-known to adversely affect many systems depending on the duration and control of hyperglycemia. It must be stressed that during patient selection, the additional risk of complications related to T2DM should be considered.

Contrary to the findings of other studies that suggest that FPG can be normalized within days after bariatric surgery in morbidly obese patients, as a result of the change in insulin resistance [28], in this study, we found that FPG improved after surgery but failed to return to normal immediately. However, as expected, the FPG and $\mathrm{HbA1C}$ values gradually declined over time, with two patients achieving euglycemia at 1 week; seven, at 1 month; and 14, at 6 months after surgery. We also observed that those who did not achieve remission at 6 months did not do so at the 12th month either. Studies on the timing of the restoration of glucose metabolism after surgery suggest that the T2DM remission occurs as a primary specific independent effect of this surgery, rather than secondary to the observed weight loss [29]. The early low resolution rates and continued improvement in glycemic parameters noted in the present study suggest that in addition to high insulin resistance,
low-BMI patients may also have a relative deficiency of insulin. We found that the mean fasting C-peptide level was $3.74 \mathrm{ng} / \mathrm{ml}$ in 10 of our patients, but very low, i.e., from 1.9 to $2.3 \mathrm{ng} / \mathrm{ml}$, in six patients. Lee et al. reported that $76.5 \%$ of patients with BMIs below $35 \mathrm{~kg} / \mathrm{m}^{2}$ met the ADA target for the treatment of T2DM at 1 year after surgery [26]. Hall et al. reported that $68.4 \%$ of the 98 patients using medications were off all diabetic medication after LRYGB [30]. Overall, 20 of our patients discontinued medication after the surgery, and only two needed to use OHGA agents at low doses; none of the patients needed insulin. The remission and glycemic rates reported in the present study are $90.9 \%$.

We assessed the age at which presentation predicts negative outcomes: elderly patients with T2DM for a prolonged duration were less likely to achieve euglycemia at 12 months. Similarly, Hall et al. reported that their patients who had diabetes for shorter durations had higher rates of remission [30]. Schauer et al. found that the magnitude of weight loss appears to increase the likelihood of resolution in obese individuals with diabetes [24]. However, in our study, the resolution of T2DM was not related to changes in BMI, although a higher preoperative BMI did predict remission. This finding confirms that the normalization of glycemic indices is not related to weight loss. Furthermore, the relatively poor outcomes related to increasing age and duration of diabetes support the notion that early surgical intervention is necessary in overweight and grade 1 obese patients with diabetes. Although this trial involved limited cases, the mean BMI was 32.4 in patients who achieved remission, and complete remission was observed in patients with a BMI of $>32$; this result precisely correlated with the Asia-Pacific surgical criteria. We recommend that further comparative studies be conducted according to the Asia-Pacific surgical criteria for diabetic remission.

\section{Conclusions}

Our study shows that LRYGB for patients with BMI in the range of $25-35 \mathrm{~kg} / \mathrm{m}^{2}$ is safe and feasible, with low early morbidity. Age, BMI, and the duration of T2DM predict glycemic outcomes at the 12th month. This study supports the notion that LRYGB can result in good remission rates in low-BMI patients with diabetes and should be considered as a method of early intervention.

\section{Acknowledgments None.}

Conflicts of Interest Drs. Huang, Shabbir, Lo, Tai, Chen, and Houng have no conflict of interest with any institution or product that is mentioned in the manuscript.

\section{Sources of Support None.}


Open Access This article is distributed under the terms of the Creative Commons Attribution Noncommercial License which permits any noncommercial use, distribution, and reproduction in any medium, provided the original author(s) and source are credited.

\section{References}

1. Wild S, Roglic G, Green A, et al. Global prevalence of diabetes: estimates for the year 2000 and projections for 2030. Diabetes Care. 2004;27:1047-53.

2. Buchwald H, Avidor Y, Braunwald E, et al. Bariatric surgery: a systematic review and meta-analysis. JAMA. 2004;292:1724-37.

3. Buchwald H, Oien DM. Metabolic/bariatric surgery Worldwide 2008. Obes Surg. 2009;19:1605-11.

4. Brancatisano A, Wahlroos S, Brancatisano R. Improvement in comorbid illness after placement of the Swedish adjustable gastric band. Surg Obes Relat Dis. 2008;4:S39-46.

5. Buchwald H, Estok R, Fahrbach K, et al. Weight and type 2 diabetes after bariatric surgery: systematic review and metaanalysis. Am J Med. 2009;122:248-56.

6. Hussain A, Mahmood H, El-Hasani S. Can Roux-en-Y gastric bypass provide a lifelong solution for diabetes mellitus? Can J Surg. 2009;52:269-75.

7. Expert Committee on the diagnosis and classification of diabetes mellitus. Report of the Expert Committee on the diagnosis and classification of diabetes mellitus. Diabetes Care. 2003;26:S5-20.

8. Huang CK, Lee YC, Hung CM, et al. Laparoscopic Roux-en-Y gastric bypass for morbidly obese Chinese patients: learning curve, advocacy and complications. Obes Surg. 2008;18:776-81. Epub 2008 May 16.

9. American Diabetes Association. Standards of medical care in diabetes: 2006, position statement. Diabetes Care. 2006;29:4-42.

10. Lee WJ, Wang W. Bariatric surgery: Asia-Pacific perspective. Obes Surg. 2005;15(6):751-7.

11. American Diabetes Association. Diagnosis and classification of diabetes mellitus. Diabetes Care. 2010;33:62-9.

12. Rubino F, Schauer PR, Kaplan LM, et al. Metabolic surgery to treat type 2 diabetes: clinical outcomes and mechanism of action. Annu Rev Med. 2010;61:393-411.

13. Gastrointestinal Surgery for Severe Obesity. NIH Consens Dev Conf Consens Statement 1991; Mar 25-27; 9(1).

14. Friedman MN, Sancetta AJ, Magovern GJ. The amelioration of diabetes mellitus following subtotal gastrectomy. Surg Gynecol Obstet. 1955;100:201-4.

15. Pories WJ, Swanson MS, MacDonald KG, et al. Who would have thought it? An operation proves to be the most effective therapy for adult-onset diabetes mellitus. Ann Surg. 1995;222:339-52.

16. Rubino F, Kaplan LM, Schauer PR. Diabetes Surgery Summit delegates. The Diabetes Surgery Summit consensus conference recommendations for the evaluation and use of gastrointestinal surgery to treat type 2 diabetes mellitus. Ann Surg. 2010;251:399405.

17. Shah SS, Todkar JS, Shah PS et al. Diabetes remission and reduced cardiovascular risk after gastric bypass in Asian Indians with body mass index $<35 \mathrm{~kg} / \mathrm{m}^{2}$. Surg Obes Relat Dis 2009;6:332-8.

18. Parikh M, Duncombe J, Fielding GA. Laparoscopic adjustable gastric banding for patients with body mass index of $35 \mathrm{~kg} / \mathrm{m}^{2}$. Surg Obes Relat Dis. 2006;2:518-22.

19. Scopinaro N, Papadia F, Marinari G, et al. Long-term control of type 2 diabetes mellitus and the other major components of the metabolic syndrome after biliopancreatic diversion in patients with BMI $<35 \mathrm{~kg} / \mathrm{m}^{2}$. Obes Surg. 2007;17:185-92.

20. Rubino F, Forgione A, Cummings DE, et al. The mechanism of diabetes control after gastrointestinal bypass surgery reveals role of the proximal small intestine in the pathophysiology of type 2 diabetes. Ann Surg. 2006;244:741-9.

21. Cohen RV, Schiavon CA, Pinheiro JS, et al. Duodenal-jejunal bypass for the treatment of type 2 diabetes in patients with BMI 22-34: a report of two cases. Surg Obes Relat Dis. 2007;3:195-7.

22. DePaula AL, Macedo AL, Mota BR, et al. Laparoscopic ileal interposition associated to a diverted sleeve gastrectomy is an effective operation for the treatment of type 2 diabetes mellitus patients with BMI 21-29. Surg Endosc. 2009;23:1313-20.

23. DePaula AL, Macedo AL, Schraibman V, et al. Hormonal evaluation following laparoscopic treatment of type 2 diabetes mellitus patients with BMI 20-34. Surg Endosc. 2009;23:172432.

24. Schauer PR, Burguera B, Ikramuddin S, et al. Effect of laparoscopic Roux-en-Y gastric bypass on type 2 diabetes mellitus. Ann Surg. 2003;238:467-84.

25. Cohen R, Pinheiro JS, Correa JL, et al. Laparoscopic Roux-en-Y gastric bypass for BMI $<35 \mathrm{~kg} / \mathrm{m}^{2}$ : a tailored approach. Surg Obes Relat Dis. 2006;2:401-4.

26. Lee WJ, Wang W, Lee YC, et al. Effect of laparoscopic minigastric bypass for type 2 diabetes mellitus: comparison of BMI $>35$ and $<35 \mathrm{~kg} / \mathrm{m}^{2}$. J Gastrointest Surg. 2008;12:945-52.

27. Fried M, Ribaric G, Buchwald JN, et al. Metabolic surgery for the treatment of type 2 diabetes in patients with $\mathrm{BMI}<35 \mathrm{~kg} / \mathrm{m}^{2}$ : an integrative review of early studies. Obes Surg. 2010;20:776-90.

28. Rubino F, Marescaux J. Effect of duodenal-jejunal exclusion in a non-obese animal model of type 2 diabetes: a new perspective for an old disease. Ann Surg. 2004;239:1-11.

29. Keating CL, Dixon JB, Moodie ML, et al. Cost-efficacy of surgically induced weight loss for the management of type 2 diabetes. A randomised controlled trial. Diabetes Care. 2009;32:580-4.

30. Hall TC, Pellen MG, Sedman PC, et al. Preoperative factors predicting remission of type 2 diabetes mellitus after Roux-en-Y gastric bypass surgery for obesity. Obes Surg. 2010;20:1245-50. 